\title{
Alternativas pedagógicas desde el territorio: praxis colectiva entre Universidad y Enseñanza Media en la periferia de Montevideo
}

Territory-Specific Pedagogical Alternatives:

Collective Praxis between the University and Secondary Education in Montevideo's Periphery

Alternativas pedagógicas do território: práxis coletiva entre universidade e ensino médio nos arredores de Montevidéu

José Agustín Cano-Menoni* iD orcid.org/0000-0001-6076-5580

Carola Patricia Godoy-Iribarne** iD orcid.org/0000-0002-5130-0607

Para citar este artículo: Cano-Menoni, J. y Godoy-Iribarne, C. (2021). Alternativas pedagógicas desde el territorio: praxis colectiva entre Universidad y Enseñanza Media en la periferia de Montevideo. Revista Colombiana de Educación, /(81), 337-356. https://doi.org/10.17227/rce.num81-11074

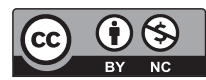

Recibido: $27 / 12 / 2019$

Evaluado: 29/03/2020

* Doctor en Pedagogía (UNAM). Universidad de la República de Uruguay, Programa Integral Metropolitano y Facultad de Humanidades y Ciencias de la Educación. Correo electrónico: acano@pim.edu.uy

** Licenciada en Psicología (UdelaR) y Profesora de Historia del Instituto de Profesores Artigas, Uruguay). Profesora de Historia en Enseñanza Media (Uruguay). Correo: cgodoyO4@gmail.com 


\section{Resumen}

Este artículo da cuenta de nueve años de trabajo conjunto entre dos entidades educativas públicas que comparten el mismo territorio de referencia: un centro de enseñanza media (el Liceo 58 Mario Benedetti) y un programa universitario (el Programa Integral Metropolitano de la Universidad de la República [PIM]). Ambas entidades están radicadas en la periferia popular del noreste de Montevideo (Uruguay). A partir de este vínculo, desde el 2012 hasta el presente numerosos proyectos educativos han reunido a docentes y estudiantes de ambas instituciones en procesos pedagógicos de inserción territorial. Estas propuestas buscan plasmar una orientación que implica poner a dialogar al centro educativo con su entorno barrial, articulando las asignaturas entre sí y a los profesores y estudiantes del liceo con sus pares de la Universidad. Con base en la reconstrucción de los principales proyectos desarrollados en casi una década de trabajo interinstitucional, territorial e interdisciplinario, el artículo propone una mirada pedagógica a dicha praxis conjunta, acudiendo para ello a referentes teóricos de los campos de las alternativas pedagógicas, la enseñanza de la historia y la extensión universitaria.

\section{Palabras clave}

enseñanza media; universidades; extensión; experiencia educativa; educación pública

\section{Keywords}

high school, universities; extension education; educational experience; public education

\begin{abstract}
This paper accounts for nine years of joint work between two public educational entities sharing the same reference territory: a secondary school (Liceo 58 Mario Benedetti) and a university program (the Metropolitan Integral Program of the University of the Republic [PIM]). Both institutions are located in the popular periphery of northeastern Montevideo (Uruguay). On the grounds of this link, from 2012 up to now, teachers and students from both institutions have met in numerous educational projects associated with territorial inclusion. These proposals seek to build an educational project that involves a dialogue between the educational center and its neighborhood. Thus, it articulates the academic subjects with each other, and the high school teachers and students with their peers from the University. After reconstructing the main projects developed in almost a decade of interinstitutional, territorial and interdisciplinary work, this paper proposes a pedagogical view of such collective praxis, turning to different theoretical references from pedagogical alternatives, teaching of history, and university extension.
\end{abstract}

\section{Resumo}

Presente trabalho representa nove anos de trabalho conjunto entre duas entidades públicas de ensino que compartilham o mesmo território de referência: uma escola secundária - Liceo n58 "Mario Benedetti" - e um programa universitário - o Programa Integral Metropolitano da Universidade de República (PIM) -, ambas Iocalizadas na periferia popular do nordeste de Montevidéu (Uruguai). A partir desse link, de 2012 até a presente data, foram realizados inúmeros projetos educacionais que encontraram professores e alunos das duas instituiçōes em projetos de trabalho territorial. O que se busca é construir um projeto educacional que envolva o diálogo do centro educacional com o ambiente do bairro, articulando os assuntos entre si e com os professores e alunos do ensino médio com seus colegas da Universidade. Após a reconstrução dos principais projetos desenvolvidos em quase uma década de trabalho interinstitucional, territorial e interdisciplinar, propõe-se uma visão pedagógica de uma práxis coletiva entre educadores de diferentes origens institucionais e disciplinares, voltando-se para diferentes referenciais teóricos de alternativas pedagógicas, do ensino da história e da extensão universitária.

\section{Palavras-chave}

Ensino médio; Universidades; Extensão; Experiência educacional; Educação pública 


\section{Introducción}

El artículo da cuenta de nueve años de trabajo conjunto entre dos entidades educativas públicas que comparten el mismo territorio de referencia: un centro de enseñanza media (el Liceo 58 Mario Benedetti) y un programa universitario - (el Programa Integral Metropolitano de la Universidad de la República ([PIM]), ambos radicados en la periferia popular del noreste de Montevideo (Uruguay). A partir de este vínculo, desde el 2012 hasta la fecha se han realizado numerosos proyectos educativos que han reunido a docentes y estudiantes de ambas instituciones, en procesos pedagógicos de inserción territorial. Así, se han puesto en marcha alternativas pedagógicas (Gómez y Corenstein, 2014) que articulan transformaciones en varios niveles, desde la relación con el currículo, las construcciones de sujeto, las relaciones educativas, y la relación con el conocimiento y los saberes. Con base en la reconstrucción de los principales proyectos desarrollados en casi una década de trabajo interinstitucional, territorial e interdisciplinario, en este artículo se propone una mirada pedagógica a dicha praxis conjunta, acudiendo para ello a diferentes referencias teóricas de los campos de las alternativas pedagógicas, la enseñanza de la historia y la extensión universitaria.

Los autores hemos participado en estas experiencias desde su inicio, pero queremos subrayar que estas han involucrado a un conjunto numeroso de colegas del liceo y la Universidad. Este texto busca ser un modesto aporte a la reflexión colectiva junto a estos compañeros, en particular quienes han conformado los grupos motores de cada proyecto.

\section{Educación pública en la periferia}

En cuestiones de cultura y de saber: solo se pierde lo que se guarda; solo se gana lo que se da.

Antonio Machado

\section{Territorio}

Un barrio, una ciudad, con sus nombres oficiales y efectivos, con sus fronteras formales y vividas, proyectan una idea de unidad que, en última instancia, resulta de una ficción. Así sucede en lo que solemos Ilamar, con excesiva simplificación, el territorio del Liceo 58 y del PIM. Como señala Herner, el territorio es

[...] una construcción social resultado de relaciones de poder que son tanto materiales como simbólicas, ya que son el resultado de la producción de un espacio que se construye diferencialmente según vivencias, 
percepciones y concepciones particulares de los individuos y de los grupos y clases sociales que lo conforma. (2009, p. 165).

¿Cómo unificar entonces lo que está conformado por una multiplicidad (de experiencias, relatos, lugares, posiciones, trayectorias) irreductible a una demarcación municipal o a una cartografía universitaria enfocada en tal o cual objeto de estudio (la economía, la educación, la vivienda)? Hablar del territorio como una unidad es una ficción. Sin embargo, el intento por forjar interpretaciones y relatos que unan los fragmentos puede ser productivo en la medida en que asumamos su condición precaria y parcial, y aun así evitemos caer en el relativismo posmoderno que renuncia a conocer. Aquí se vuelve crucial el método: ¿cómo dar cuenta de una totalidad que no suprima su multiplicidad constitutiva? Al modo del científico social, sin dudas: observando, midiendo, identificando problemas transversales, historizando, relacionando partes, interpretando tendencias, indagando en lo que no se ve, ya sea por exceso de oscuridad o de luz. Pero también al modo del cronista, siguiendo el consejo de Néstor García Canclini: "'Lo infinito requiere de estrategias para volverse próximo': hacer cercano lo desconcertante, asediar los puntos en que se manifiesta el desorden de modos en que parece urbano" (2018, p. 18).

Según datos del Censo 2011, el Municipio F (principal referencia territorial del PIM) cuenta con una población de 168.937 habitantes (1988 hab. $/ \mathrm{km}^{2}$ ), de los cuales un 99,3 \% es población urbana. ${ }^{1}$ El porcentaje de personas con al menos una necesidad básica insatisfecha es de 40,6, valor que supera tanto al promedio departamental $(26,8 \%)$ como al nacional $(33,8 \%)$. También la tasa de desempleo es superior a la departamental y la nacional, con una tasa de actividad de $63,4 \%$, una tasa de empleo de $58,4 \%$ y una tasa de desempleo de $7,8 \%$. Los indicadores educativos se encuentran también más pauperizados que los promedios de Montevideo y Uruguay: el analfabetismo llega al 1,6 \% de la población de 15 años y más del municipio; y las tasas netas de asistencia a educación primaria y media son de $91,4 \%$ y de $60,7 \%$ respectivamente (mientras que el promedio departamental es 92,4\% y 69,8\% para cada nivel) (Oficina de Planeamiento y Presupuesto, 2019).

La problemática de los asentamientos irregulares tiene también un fuerte impacto en el territorio de referencia del PIM, al punto que, según un estudio del 2009, allí se encontraban entonces el $18 \%$ de las personas que viven en asentamientos irregulares (Mendy, 2012). Si bien este dato tiene ya una década, una investigación reciente sobre la evolución de los asentamientos irregulares en Uruguay en el periodo 2006-2018 ha evidenciado que la cantidad de asentamientos irregulares en el país solo tuvo un leve descenso en dicho marco temporal. Esto pone en evidencia que se trata de un fenómeno estructural que da cuenta de una modalidad 
estable de acceso a la vivienda por parte de un gran sector de la población con menores ingresos, que queda excluida del mercado del suelo. Dentro del total, Montevideo se comporta como el promedio y Canelones fue el único departamento que registró un leve aumento (Ministerio de Vivienda Ordenamiento Territorial y Medio Ambiente, MVOTMA, 2019). El estado del arte es coincidente en señalar un conjunto de problemáticas asociadas a esta, que reflejan la vulneración de derechos fundamentales en las poblaciones que allí viven, así como problemas relacionados con la propia organización de la ciudad. ${ }^{1}$

Hasta aquí una muy somera y parcial presentación de algunos rasgos de los territorios de referencia del Liceo 58 y el PIM. Lo que interesa señalar es que, junto a la producción y actualización de la mejor y más completa información estadística posible sobre el territorio, para poder "asediar los puntos en que se manifiesta el desorden", es necesario dar un paso más y procurar poner en marcha dispositivos de investigación y extensión que puedan desentrañar las redes de relaciones que lo producen. Quizá a esto se refiere Fernández Christlieb cuando propone que a una ciudad, "a los barrios, las conversaciones, los géneros, la publicidad, se los puede mirar como conglomerados, luchas, danzas, economía, naturaleza, política, poder, pero se los puede ver como siendo un pensamiento" (2019, p. 23). En buena medida, tal es el movimiento que debería buscar la integralidad del quehacer articulado de la educación pública en esta escala: producir un pensamiento desde y sobre el territorio (y también más allá de este) que pueda dialogar con otros pensamientos en la producción de nuevas interpretaciones, sentidos y alternativas.

\section{Instituciones}

El trabajo articulado entre Universidad y Enseñanza Media a nivel territorial es una orientación más sencilla de formular que de Ilevar a cabo. Implica sortear dificultades de diferente índole, desarmar viejos prejuicios y múltiples nudos que traban diálogos en el devenir formativo de los sujetos que transitan

1 Burdín (2019), citando una investigación de Mariana Rodríguez, señala, para el caso de Montevideo, que la segregación residencial por nivel de educación y ocupación aumentó en el periodo 2006-2017, y observa que la batería de políticas públicas enfocadas en mejorar las condiciones de infraestructura de la periferia, por importantes que sean, no operan sobre el problema de la segregación. Como ha propuesto el Núcleo de Territorio, Comunidad y Derechos Colectivos del PIM, el problema debe comprenderse desde el marco conceptual de la desigualdad económica, la segregación residencial y las luchas por el uso del territorio, lo cual permite descentrar el foco de los sectores populares, y ubicarlo en el complejo de relaciones y condiciones que producen el problema de la segregación social y territorial, incluyendo, en el caso que nos ocupa, a los "enclaves informacionales capitalistas" como Zonamérica (Falero, 2012) y las apropiaciones del territorio por parte de las clases altas (como los barrios privados). Sobre el marco conceptual para el estudio del tema, véase Pérez et al. (20189. 
las instituciones educativas. La institución de educación media en Uruguay (liceo) trabaja con estudiantes de entre 13 y 18 años, y la institución universitaria con estudiantes mayores de edad, con su ciclo de educación media terminado. Pero, salvo algunos programas específicos (véase por ejemplo Santiviago et al., 2015), no es común que existan continuidad ni acciones educativas compartidas entre ambas instituciones. ${ }^{2}$ No suelen convivir en su tarea formativa y de enseñanza los docentes universitarios con los docentes de educación media, ni los estudiantes adolescentes con los universitarios. El trabajo que narraremos se basa en poner a dialogar y construir en conjunto a estas partes desde el nivel micro y situado de la experiencia pedagógica en territorio.

Desde el 2012 hasta el presente, cada año se ha realizado un proyecto nuevo basado en un dispositivo de intervención que se ha mantenido en el tiempo. Dicho dispositivo, elaborado en conjunto en el proceso de la práctica, ha demostrado ser efectivo para sortear las dificultades de tipo organizativo que surgen de la articulación entre dos instituciones con organizaciones académicas y regímenes laborales-docentes muy diferentes. Lo que se busca, cada año, es construir un proyecto educativo que ponga a dialogar al centro educativo con su entorno barrial, articulando las asignaturas entre sí y a los profesores y estudiantes del liceo con sus pares de la Universidad. Las propuestas se construyen en conjunto entre los docentes universitarios y los profesores del liceo, y se basa en los objetivos y contenidos curriculares de sus respectivos programas.

Para poder concretar los proyectos fue necesario sortear varias dificultades que se presentaron a priori o en el transcurso del trabajo. ¿Cómo romper con cierta tendencia endogámica de la academia, la rigidez institucional de la enseñanza secundaria, la tendencia a asociar educación con enseñanza en el aula, o las prácticas institucionales cerradas? El diálogo mutuo fue el generador de saberes y prácticas colectivas. Se habilitó la producción compartida de un saber, o multiplicidad de ellos, que fueron dando forma a la gestación de proyectos que llegaron a involucrar a entre 20 y 200 integrantes, a varias generaciones de estudiantes y a múltiples instituciones barriales.

2 En el transcurso del 2019 se realizaron algunos avances en esta dirección, que concluyeron en la firma de un convenio para diferentes proyectos compartidos que incluyen el trabajo en las interfaces y las trayectorias educativas entre Enseñanza Media y Universidad. 


\section{Proyectos pedagógicos compartidos entre el PIM y el Liceo 58}

\section{Acercamiento de "otredades"}

Como se mencionó, el centro educativo se encuentra en un barrio de la periferia que suele estigmatizarse por su condición de sector popular y su lejanía del centro de la capital de Montevideo. Más que de un barrio, se trata de un conjunto de barrios obreros, marcados por dificultades económicas y materiales, junto a asentamientos del tipo de las "villas", construidos y habitados por familias que han sido excluidas de los circuitos del trabajo formal, la vivienda y el acceso a sus derechos.

Uno de los desafíos fue el de revertir la construcción de sentidos negativa que suele existir ligada a estos lugares, asociada a las dinámicas de segregación entre centro y periferia, que además de materiales son también simbólicas. A través de una dignificación de la historia de los barrios, una comprensión colectiva de su trayectoria y una construcción narrativa que denomine el espacio y el territorio desde una definición menos prejuiciosa y menos cargada de negatividad fue posible iniciar un diálogo pedagógico e intergeneracional desde otras bases. Esto implicaba un trabajo sobre la identidad primaria, eso que se recoge en las expresiones de los estudiantes de barrios rojos, de robos, periféricos, ese lugar donde aparentemente nadie quiere llegar y del que se presupone que quien allí vive siempre desea salir. Uno de los interrogantes fue: ¿cómo lograr modificar o, por lo menos, cuestionar las representaciones ligadas al barrio, a su liceo, a su entorno? ¿Y por qué no, a ellos mismos, a los sujetos que habitan y allí trabajan? El barrio como espacio urbano es donde se construye una identidad primaria que se experimenta en la cotidianeidad de vida. Esa identidad es productora de subjetividad.

¿Qué pasa cuando los discursos hegemónicos narran una identidad de barrio marginal, pobre, de "chorros", inseguro, de delincuentes? Estos discursos emanan de lo que construyen los medios de comunicación dominantes, de la propia exclusión socioeconómica que genera el capitalismo, y un sinfín de significaciones construidas socialmente. En estos espacios urbanos se recorta lo real, se resalta la crónica roja, se estigmatiza la pobreza y se condena material y discursivamente a sus habitantes. Y en esa dotación de sentido cultural, ideológico, en esa semántica, crecen y se forman nuestros estudiantes. Parte de nuestra tarea es deconstruir algunos de esos discursos y promover otras prácticas pedagógicas que doten de otra semántica, otra significación de su pasado y de su presente, aspirando a la transformación en un sentido profundo. Es decir, en un sentido diferente al de las propuestas de empleabilidad rápida en empleos de malas condiciones, que bajo la forma de "inclusión educativa", con frecuencia tienen un efecto de reforzamiento de la exclusión (Martinis, 2016). 
La primera consigna era retomar palabras como dignidad, trabajo, resistencia, trabajo colectivo, gestando una tarea de deconstrucción de relatos y resignificación de la memoria. Los objetivos no eran exclusivamente académicos. Aspiraban a trascender las paredes institucionales y adentrarse en el barrio, en las historias vitales, en trayectos particulares y colectivos. Y aquí vale la pena una pequeña pausa para debatir el lugar del saber y de los saberes. ¿Quién porta el saber? Quizás nos sirva pensar en el aporte que extraemos del psicoanálisis lacaniano la herramienta conceptual del "sujeto supuesto saber". Existe una ficción compartida social y académicamente con relación a la jerarquía del saber del académico, del técnico, y el saber que portan los adolescentes del barrio, el que no siempre aparece disponible como referencia con la cual trabajar y a la cual recurrir. ¿Cuál es ese saber? ¿Cómo nos acercamos a él y promovemos su emergencia? Sin duda un primer paso es promover la potestad, el derecho y lo vital de un ejercicio de pensamiento que no se delega en otro. Como recuerda Jacques Rancière a partir de las enseñanzas de Jacotot: "La instrucción es como la libertad, no se da, se toma" (2007, p. 138). Esto tiene que ver con la dignificación, en educación, de la tarea de pensar, y de un pensar que se pone en relación con una práctica. Pensar distinto, hacer transformador: vivencias, acciones, recuerdos y construcciones de relato que son portadores de un saber-hacer. En este planteo, el académico, el docente, en la metáfora que tomamos de Lacan, el "analista", acepta ser parte de esa ficción de ser el poseedor del saber, pero solo para vehiculizar ese encuentro con esa "verdad", que se porta y a veces se desconoce. Esa tarea, poco narcisista y muy habilitadora, es la que intentamos emprender en un movimiento de pasar la posta al barrio, tender un puente a los "viejos", ampliar la conversación pública entre el centro educativo y su contexto, poner a los estudiantes a intercambiar con las organizaciones barriales. Mismo barro con el que el equipo de docentes y estudiantes del PIM, así como el de docentes liceales, se nuclearon y enchastraron (en la maravillosa imagen del niño necesariamente enchastrado para empezar a crear) cada año intentando sumar ideas que se volvieran acciones transformadoras de lo real. De nuestra realidad laboral, de la realidad de la enseñanza, de los aprendizajes y de las prácticas pedagógicas.

El trabajo de varios años circuló por variados carriles. Desde el empoderamiento y la reconciliación de los docentes y trabajadores con su rol, su lugar, su potestad como profesionales críticos, emancipadores y transformadores de su realidad y de la que los rodea. Colaborar y trabajar por salirse del lugar de la queja y la denuncia catártica, para volverla proyecto, acción, acto creativo y generación de cambio. Esta apuesta por transformar lo que denunció, en cambio, es un paso clave para iniciar el trabajo. Para los docentes o cualquier actor social que trabaja en 
instituciones de estas que llamamos "periféricas", la saturación de problemáticas sociales por resolver, además de la propia tarea específica, hace que muchas veces la angustia y la impotencia paralicen. Y la sola queja es una paralización, una obturación de la capacidad de pensar y de transformar (Fernández, 1998).

\section{Los nuevos "jinetes del apocalipsis": malas prácticas pedagógicas, malos enseñantes, crisis de la educación, nueva población necesitada de una nueva evangelización}

Estas prácticas pedagógicas implican una nueva y valiosa formulación del quehacer de la enseñanza. No nueva en cuanto reciente, o innovadora, ya que "buenas prácticas pedagógicas" existen por doquier y desde hace tiempo. El tema es que muchas de ellas se encuentran invisibilizadas, ocultas, anónimas. Valiosa en cuanto es la apuesta consciente a dos tareas: la de restitución (resignificación) y la democratizadora. Restituir y resignificar la tarea de enseñanza y de socializar saberes. La de producirlos entre actores institucionales y barriales, o sea producirlos colectivamente, y la revalorización del papel de la educación pública en los barrios, en tiempos de relatos de crisis de la educación y de mercantilización de esta. Y aquí interesa especificar la discrepancia con el relato mediático que instala la idea de crisis como deterioro irreversible. Y no como algo que es inmanente a toda actividad y acción social, o que involucre sujetos en constante transformación, sino como aquellos que nos preocupa y nos amenaza. La crisis, en lugar de ser aquello que le es propio y necesario a la transformación humana, portadora incluso de un valor epistemológico en el sentido en que lo ha trabajado Sztulwark (2019), aparece discursivamente como una amenaza por combatir. O bien como un diagnóstico inapelable que justifica un paquete de reformas en general asociado al neoconservadurismo pedagógico (Apple, 2012).

Otros de los macrorrelatos que golpean a las instituciones educativas es el de construir y reforzar la idea de nuevos enemigos: la agenda de derechos, la educación sexual ajustada a los cambios en el pensamiento ligado a género y patriarcado. Parte de la "aporofobia" es pensar al que vive y se educa en barrios periféricos como el nuevo "indígena" por evangelizar, es el pobre, el inmigrante, el "de la curva". Herencias de prácticas estigmatizantes, en el cual el diferente, lo heterogéneo, es condenable, se vuelve peligroso. Y parte de la repetición de este pensamiento se expresa en la proliferación de políticas focalizadas que reproducen la dinámica de segregación educativa, con propuestas pobres de contenidos y de proyección, para sujetos que imaginan vacíos de contenidos y sin proyección vital. Doble error. 


\section{Aportes para la enseñanza de la historia en el nivel secundario}

La tarea educativa es clave para cuestionar y transformar nuestras sociedades que perpetúan la exclusión, la marginación y la segregación material y cultural. Una educación que sea capaz de desnaturalizar las situaciones dadas, aportar nuevos significados y sentidos para la comprensión e interpretación del mundo, y dotar de herramientas transformadoras. Parte de ese proceso de concientización tiene que ver con la deconstrucción de metarrelatos existentes que funcionan como sentido común hegemónico. La sociedad construye y se constituye mediante el lenguaje, y la palabra tiene sentidos y es creadora de realidad. En este sentido, acción y palabra construida, revisada y vuelta a construir son herramientas de transformación de la realidad.

En esa tarea nos embarcamos como colectivo pedagógico en cada proyecto creado, pensado, revisado y transitado. Como en el efecto bola de nieve, cada propuesta comenzaba con breves pero ambiciosas ideas y luego iba creciendo con el aporte de los diferentes participantes. A continuación presentaremos solo tres ejemplos de un conjunto de experiencias realizadas en ocho años de trabajo conjunto: los proyectos Memoria que es vida abierta (2013-2014), Me gustan los estudiantes, homenaje al68 estudiantil en el mundo (2018) y Huellas de Mario Benedetti (2019-2020).

\section{Proyecto Memoria que es vida abierta}

Nació con la intención de conmemorar los cuarenta años de la Huelga General en Uruguay, en 1973. Este hecho histórico consagra la resistencia de la Convención Nacional de Trabajadores (CNT) ante el golpe de Estado cívico-militar de dicho año.

Esta propuesta se desarrolló a lo largo del 2013, y fue el primer gran proyecto gestado en conjunto entre el Liceo 58 y el PIM. En el caso del liceo, participó sobre todo la Sala de Historia, convocando a más de 350 estudiantes de Educación Media que trabajaron junto a varias organizaciones barriales. La trama del proyecto fue trabajar con estudiantes de cuarto grado de Educación Media (jóvenes de un promedio de edad de 16 años), que buscaran en la memoria barrial, entre sus vecinos, familiares, las narrativas en torno a las diferentes expresiones de la resistencia a la dictadura que habían existido en el barrio. La resistencia en dicho barrio tenía mucha importancia, ya que el centro educativo está emplazado en un barrio obrero, zona de viejas curtiembres y fábricas. Un viejo enclave de la industrialización de las décadas de 1940 y 1950, heredera del modelo de industrialización por sustitución de importaciones (ISI) que se implementó a mediados del siglo xx en Uruguay y varios países de América Latina. 
La tarea implicaba salir a la búsqueda de esos actores invisibles, algunos olvidados, pero que en sus memorias particulares contenían trozos de piezas de la historia barrial y la resistencia contra la dictadura. La estrategia montada contempló la propuesta de que el proyecto formara parte del trabajo curricular anual del curso de Historia, incluyendo sus instancias de evaluación. Así comenzó, una serie de reuniones de planificación mediante la malla que conformó una red de actividades anuales de gran significación y formación para los estudiantes, para los docentes tanto universitarios como de Educación Media, para los "viejos del barrio" y para varias instituciones. Dotar de sentido el pasado, re-pensarlo, cuestionarlo, rescatarlo, a través de la acción, la proyección colectiva, el ejercicio y diálogo de las memorias, y la palabra de dos generaciones que suelen estar muy distanciadas: la de los jóvenes entre 15 y 16 años, y quienes tienen más de 60.

La preparación implicó talleres informativos y formativos acerca de entrevista histórica, filmación, fotografía, historia y pasado reciente (periodo dictatorial 1973-1985 en Uruguay y dictaduras del Cono Sur, década de los setenta), homenajes a personajes de la época, 4 cortos documentales elaborados por estudiantes del liceo y de la Facultad de Ciencias de la Comunicación, 6 recorridos históricos por la zona del casco de viejas fábricas guiados por protagonistas de la época, 8 instalaciones artísticas producidas entre estudiantes del liceo y estudiantes de Facultad de Bellas Artes. Se sumaron al archivo 70 entrevistas a protagonistas históricos, y una muestra patrimonial con documentos, fotografías y objetos de época. También se realizaron visitas a distintos archivos históricos, como los existentes en la Biblioteca Nacional, y se trabajó con colectivos vinculados al tema (García et al., 2015).

En Uruguay entre 1985, año de la restauración democrática, y el 2005 primó y se fue institucionalizando una idea de "memoria dominante" que pautaba un "dar vuelta a la página", "mirar al futuro", algo que llamaremos las políticas del olvido. Pero diversas comunidades locales, barriales, sindicales, intelectuales, de familiares, hemos peleado por las políticas de memoria. Álvaro Rico (2005), historiador uruguayo, plantea que aquellos que fueron tildados de "violentistas" sostuvieron una memoria resistente, que lucha por recordar, investigar, penalizar y debatir el pasado reciente; que demanda justicia sobre los crímenes de lesa humanidad, sobre el terrorismo de Estado y las violaciones a los derechos humanos así como por el ataque a la democracia. Ese "olvido activo" que señala el historiador se liga con ese pasado autoritario que se pretende borrar y ocultar. Muchos han sido en Uruguay y en toda América Latina los combates por la restitución de la memoria histórica ligada a la historia reciente (décadas de 1970 y 1980). Esta tarea también es parte de la reconstrucción de la memoria barrial, colectiva, social y cultural. Nos encontramos con una bella tarea de transmisión transgeneracional y restauración de un lazo de generaciones.

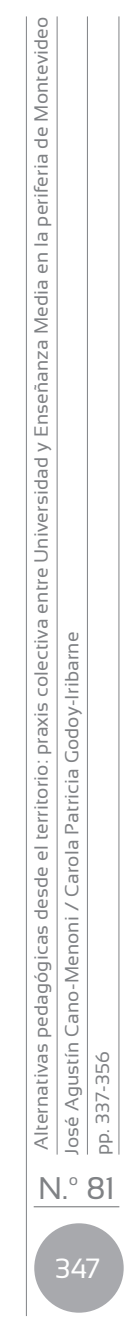


Ciertos saberes circulaban entre edades, grabaciones, trabajos académicos y relatos de aula. Las entrevistas a los testigos, a los "viejos", restablecía el pasado en las aulas para darle un sentido y habilitaban la contextualización. Para muchos de estos hombres y mujeres, dañadas, afectadas por el terrorismo de Estado y a veces por algo tan temible y violento como el olvido, significó un hito afectivo, el hecho de poder aportar su vivir y resistir a jóvenes generaciones preocupadas por saber.

Este texto no logra transcribir todos los alcances que desplegó el proyecto Memoria que es vida abierta. ${ }^{3}$ Pero quizás uno de sus efectos mariposa fue el de dar fuerza y sembrar una semilla para nuevos desafíos.

\section{La importancia del efecto mariposa: homenaje a los movimientos estudiantiles del 68}

Tiempo después de haber logrado desarrollar de buena forma un proyecto de las dimensiones de Memoria que es vida abierta", surgió la idea de homenajear al emblemático año 1968. Así, en el verano del 2018 se empezó a gestar la idea de recordar, a cincuenta años del mayo francés, del movimiento estudiantil mexicano y la masacre de Tlatelolco, y de muchos otros 68, de Uruguay y el mundo, la importancia de la rebeldía estudiantil y juvenil. También se incorporó la referencia a los cien años de la revuelta estudiantil de la Reforma de Córdoba de 1918. El proyecto se desarrolló a lo largo del 2018, y constó de diversas actividades dentro y fuera del liceo. Docentes y estudiantes de Bellas Artes, del Archivo General de la Universidad, y de Facultad de Humanidades y Ciencias de la Educación, junto a profesores y alumnos del Liceo, indagaron desde diferentes enfoques y abordajes un diálogo intergeneracional que, a partir de 1968, propició la reflexión de los jóvenes en su propio tiempo y circunstancia.

Retomar la idea del efecto mariposa, o aquello que no se puede planificar y anticipar pues empieza a rodar en los acuerdos colectivos, en la construcción de un hacer en conjunto, de reflexión en el andamiaje del proyecto, que siempre ha superado ampliamente la planificación inicial. Reparar en este formato de trabajo es propio de los haceres colectivos y es de gran trascendencia. Ya que la praxis colectiva no procede de escritorios ni de saberes técnicos, emana de un saber-hacer en territorio, en acción. Es así donde surge entre profesores de Historia y Filosofía, en diálogo con docentes de la Escuela Nacional de Bellas Artes, la idea de poner a circular entre los adolescentes, los afiches confeccionados por los estudiantes franceses en el 68. Sus protestas, su "Prohibido prohibir, la libertad comienza por una prohibición", "imaginación al poder", "Fábrica,

3 Se puede conocer más sobre esta experiencia en García et al. (2015), dttp://pim.udelar. edu.uy/actores_sociales/memoria-que-es-vida-abierta/ 
universidades, unión", entre otras emblemáticas consignas, son signos de un década de lucha y protesta ante el orden establecido. Se trabajó con nueve grupos de Enseñanza Media a los que se formó en talleres de Artes Gráficas, Lenguaje Serigráfico y Fabricación de esténciles que emulaban el accionar estudiantil de aquella época. Al igual que los jóvenes del 60, la consigna se trataba de crear sus propias denuncias actualizadas a la segunda década del siglo xxı latinoamericano. El mismo trabajo se realizó en lenguaje cerámico.

Lo logrado no solo tuvo que ver con la puesta en práctica de un diálogo de saberes, sino también de épocas, de generaciones, de diferentes sentidos respecto al pasado histórico reciente, en un trabajo colectivo de resignificación en la actualidad: estudiantes de 16 y 17 años, expresando sus denuncias y cuestionamientos de la sociedad en la que viven, estimulados en cierta forma por la lucha generada por los jóvenes de una década emblemática, como 1968. Las reflexiones y el estudio de lo sucedido medio siglo atrás se puso también en relación con los sucesos y situaciones de la actualidad en América Latina. Así, por ejemplo, se abordó el tema de la desaparición de los 43 estudiantes de la Escuela Normal de Ayotzinapa, México, en septiembre del 2014. Esto se hizo a partir de una muestra de obras plásticas sobre la temática, realizada por estudiantes y docentes de Bellas Artes (pertenecientes al Taller Alonso), y expuestas en la fotogalería a cielo abierto del PIM. Junto al recorrido de la muestra, y la puesta en palabras de las afectaciones en los cuerpos ante el contacto con el horror a través de las obras que lo interpretaron, se realizó también una mesa redonda en la que arqueólogos y miembros del Museo de la Memoria dialogaron con los estudiantes sobre los esfuerzos actuales en la búsqueda de las personas desaparecidas por la dictadura uruguaya en la década de 1970. De este modo, los contenidos curriculares cobran otro sentido, y el vínculo de los estudiantes con el conocimiento sucede con el trasfondo de un trabajo colectivo e intergeneracional de construcción de memorias y sentidos.

\section{Huellas de Mario Benedetti}

Finalmente, durante el 2019 (y se planea continuar en el 2020) se desarrolló el proyecto "Huellas de Mario Benedetti", que busca profundizar en las diferentes áreas de actuación y la vida de este autor multifacético, a cien años de su nacimiento. Para ello, el proyecto procura poner en diálogo diferentes disciplinas para intentar nuevas miradas sobre el autor, su vida, su época y su obra. Se trata de un proyecto en curso que hasta ahora ha convocado a todos los ciclos del liceo, además de docentes y estudiantes universitarios de Bellas Artes y la Facultad de Humanidades y Ciencias de la Educación. Algunas de las acciones realizadas han sido 
la musicalización de poemas de Benedetti en el género rap por parte de alumnos y alumnas del liceo; la discusión del Benedetti ensayista con profesores de filosofía, la creación en obra gráfica y piezas de cerámica a partir de textos del autor, reapropiados y recreados por los alumnos, y la realización de obras de teatro, entre otras acciones. Para ello han participado, trabajando en el liceo, docentes y estudiantes de Bellas Artes y de la Facultad de Humanidades y Ciencias de la Educación, al tiempo que los estudiantes del liceo han recorrido locales universitarios, trabajando en los talleres de Bellas Artes para la confección de sus piezas.

\section{El lugar del arte}

Desde el comienzo, entre las disciplinas participantes, cobró particular fuerza la participación de los equipos del Instituto Escuela Nacional de Bellas Artes de la Universidad, articulando, sobre todo (aunque no únicamente) con los bachilleratos artísticos del liceo. Los lenguajes artísticos, en sus diferentes géneros (gráfica, plástica, artes del fuego, fotografía) y soportes, revelaron una gran potencia pedagógica al menos en dos sentidos: 1) como lenguajes, enunciaciones, que enriquecieron la comprensión, interpretación y reflexión sobre los temas trabajados; 2) como medios de expresión para que los estudiantes pudieran pensar y comunicar mensajes que por otros medios les era más difícil transmitir. A su vez, a través de las artes se dialogó con el territorio, creando instalaciones en determinados lugares, pintando murales, esténciles, entre otras iniciativas en la que los estudiantes imprimieron su huella, embellecieron su entorno y habitaron de nuevas formas el espacio público, transformándolo.

\section{Aportes a la formación universitaria}

Como hemos desarrollado en otras oportunidades (Cano et al., 2015, 2019), el trabajo con el Liceo 58 le ha permitido a la Universidad, a través del PIM, generar un Espacio de Formación Integral (EFI) desde el cual promover que los estudiantes universitarios se formen en procesos de extensión como parte de sus actividades curriculares. Esto impacta en la formación universitaria de diferentes modos (Cano y Castro, 2016; Tommasino y Stevenazzi, 2016). Como es una idea aceptada en la literatura en la materia, el papel de la producción de conocimiento es el factor que distingue a la reflexión pedagógica universitaria de la investigación pedagógica en otros niveles educativos, la cual suele estar centrada — como observa Behares- en el modelo de la "transmisión" de determinados contenidos previamente procesados por operaciones de "transposición didáctica" y sobredeterminados por la lógica y la política del currículo 
(Behares, 2011). ${ }^{4}$ En el caso de la universidad, en cambio, los procesos de enseñanza se organizan, en el plano normativo, ya no desde la lógica de un conocimiento estandarizado instrumentalizado como contenido por transmitir, sino desde el contexto mismo de un "campo de saber en funcionamiento" (lógica de la investigación) donde los procesos de enseñanza son subsidiarios al funcionamiento mismo de ese campo de saber (Behares, 2011). Esto tiene una particular importancia en el caso de la extensión, dado que las experiencias de extensión integradas a la formación curricular que alcanzan mayor potencia pedagógica son aquellas que se estructuran como procesos de investigación (Cano y Castro, 2016).

Se logran así dos tipos de objetivos que han estado en el centro de las reflexiones pedagógicas sobre la extensión: mejores aprendizajes, en la medida en que se incorpora un nivel de práctica junto a los contenidos trabajados en el aula, y junto con ello, procesos formativos que implican experiencias que conmueven a los estudiantes respecto a sus ideas y sentimientos previos. Es decir, además de aprender conocimientos nuevos, se incorporan nuevos modos de relacionarse con los conocimientos y los sujetos, junto a una reflexión ética y política sobre los emergentes de la praxis y el propio lugar como futuro profesional. Para los estudiantes que se forman en temas educativos, además, la participación en estos proyectos, desde esta perspectiva pedagógica, política y epistemológica, resulta de una gran importancia formativa y experiencial, para debatir los relatos dominantes sobre los problemas educativos que circulan en nuestra sociedad.

\section{Alternativas pedagógicas y territorio}

Cotidianamente, los medios de comunicación y los usos de las pruebas estandarizadas tipo PISA nos brindan insistente evidencia sobre la impotencia de las instituciones educativas ante algunas de las problemáticas que enfrentan. Pero sabemos bastante menos sobre las creaciones pedagógicas que los educadores realizan para abordar dichas problemáticas, o a pesar de ellas, desde el nivel de las experiencias (Larrosa, 2003).

Una construcción teórico-metodológica dirigida a indagar las experiencias alternativas dentro del campo problemático de la educación ha sido la del Programa Alternativas Pedagógicas y Prospectiva Educativa en América Latina (Appeal) conformado por investigadores de la UBA y la UNAM.

4 La noción de "trasposición didáctica" pertenece a Chevallard (1998). En modo alguno se trata de la única concepción al respecto en la enseñanza preuniversitaria. Así, por ejemplo, en nuestro medio, Zavala (2012) ha sustentado, para el caso de la enseñanza de la historia, una construcción integrada entre práctica de enseñanza y procesos reflexivos y creativos ("investigación práctica") de los profesores en diferentes planos desde su quehacer. 
Dicho programa ha construido un conjunto abierto de referentes teóricos, articulados en una propuesta metodológica de sistematización de experiencias que permiten abordar el estudio de lo educativo, a la vez en su autonomía relativa y su relación con los procesos sociales históricos que lo sobredeterminan (Gómez y Corenstein, 2014). Así, lo hegemónico y lo alternativo no constituyen estados puros que se alcanzan, sino lógicas que se tensan y disputan con fuerza desigual en la producción de contenidos, formas, sentidos y significados relacionados con lo educativo. ${ }^{5}$

Así, más que una posición esencial que se tiene o se alcanza, lo alternativo como lógica analítica produce un campo de reflexión que permite dar cuenta de la complejidad de los procesos en varios planos. Lo alternativo se juega en relación a los sujetos que forman parte de las propuestas, y que en este caso provienen de sectores históricamente excluidos del derecho a la educación; con respecto al currículo y los métodos de enseñanza; en referencia a las relaciones educativas en torno al currículo, el saber y el territorio. En su propuesta teórico-metodológica Gómez et al. (2014, p. 55) establecen tres dimensiones de análisis de las experiencias: 1) el "ethos" (referido al conjunto de "ideas que justifican la necesidad del cambio y del futuro imaginado"); 2) "lo procedimental" (las acciones e iniciativas - y sus condiciones de producción- que se realizan para que lo alternativo se conforme y afecte a las situaciones que quiere transformar); y 3) "lo pedagógico" (refiere a la caracterización de los rasgos específicamente educativos-pedagógicos particulares de cada experiencia). Organizadas en torno a estas tres dimensiones de análisis, estas autoras han construido un conjunto de diez categorías intermedias que tornan operativos a los objetivos y preguntas de investigación:

» Para la dimensión del ethos, las categorías Proyecto ético político, Trascendencia, Articulación sujeto-estructura, Problemática a la que responde.

» En la dimensión de lo procedimental, las categorías Estrategias, Saberes, Sujetos, Grados y relaciones de institucionalización y Base material.

» En la dimensión de lo pedagógico, la categoría intermedia Modelo educativo (Gómez et al., 2014, pp. 55-57).

Tomando estas referencias analíticas, es posible pensar los proyectos pedagógicos reseñados en sus niveles de alternatividad, y junto con ello, también en sus limitaciones para avanzar más allá de sí mismos y posibilitar cambios estructurales. En la perspectiva planteada, el territorio se desdobla

5 En este sentido, no se trata de considerar lo alternativo como portador de una virtud intrínseca o a priori, como propaga cierto discurso de mercadeo educativo. De lo que se trata es de examinar los sentidos y contenidos asignados a las construcciones alternativas, incluyendo la re-articulación de elementos propios de las tradiciones hegemónicas. 
de su condición inicial de mero contexto, y cobra centralidad productiva en procesos de investigación participativa que, al mismo tiempo, resignifican y recrean los contenidos de enseñanza curricular, tanto como los significados y sentidos con que percibimos y dialogamos sobre los modos de habitar y convivir en la ciudad. Se problematizan imaginarios e identidades cristalizadas vinculadas a la peligrosidad y la carencia, al tiempo que se profundiza sobre las redes complejas de causalidad de las problemáticas existentes y percibidas, tanto en sus aspectos económicos como culturales. Se ensayan estrategias y formas de vinculación entre los centros educativos y sus contextos barriales que tienen características y sentidos diferentes a la propuesta dominante que concibe dicha relación como una adaptación del adentro de la escuela al afuera de relaciones mercantiles. Aquí el centro educativo ocupa un lugar diferente a su afuera, habilitando por ello nuevas posibilidades de existencia y convivencia, pero a la vez se vincula con su entorno de modos que el trabajo pedagógico de docentes y estudiantes no se interrumpe, sino que se juega en diferentes ámbitos. Las enseñanzas, los aprendizajes, los contenidos curriculares, las relaciones educativas y los procesos de formación se reorganizan así de modos novedosos y potentes. Con todo, las experiencias reseñadas hasta el momento no han podido ir más allá de su tiempo y duración, por tanto no han tenido mayor impacto a nivel organizacional e institucional. Funcionan así como espacios alternativos acotados que no alteran estructuralmente el funcionamiento normal de las instituciones, que con sus marcos normativos e institucionales, sus regímenes laborales y sus formas de evaluación, obturan muchas veces las posibilidades de coordinación interinstitucional y trabajo fuera de las aulas.

\section{Reflexiones finales}

¿Cuál es la tarea de los actores educativos con vocación transformadora dentro de un orden social de exclusión y segregación? Pensamos que la praxis colectiva transformadora en las condiciones existentes, buscando desbordarlas y articular esfuerzos para cambiarlas. En este sentido, cobra importancia el debate y posicionamiento ético-político dentro de la educación pública y en el trabajo en territorio. El antropólogo francés Dany-Robert Dufour (2009) habla de un consumo de las personas, de una discreta antropofagia del capitalismo global, constructora de subjetividades desde un reduccionismo mental, semántico e ideológico acorde a la dinámica socioeconómica actual. Es en este marco donde reivindicamos un sentido fuerte de la tarea de educar, dentro del cual debe incluirse la reflexión sobre la enseñanza. Allí se abre la posibilidad de pensar pedagógicamente prácticas transformadoras que articulan colectivos, instituciones, saberes, docentes, estudiantes y actores barriales. Tarea no exenta de tensiones, 
dificultades y resistencias: todas las implementaciones de los proyectos han ocasionado problemas; actores no interesados, resistencias al trabajo colectivo, dificultades burocráticas que en ocasiones producen desaliento. Es necesario generar una construcción de política educativa que extraiga aprendizajes de las experiencias, y logre transformar las propias estructuras organizativas y las condiciones materiales desde las que se desenvuelven, las que muchas veces restringen las posibilidades de trabajo. Con todo, las dificultades han sido asumidas como parte de la construcción de cualquier proyecto transformador. Por lo demás, los resultados han dignificado y resignificado la tarea de enseñar, la de aprender y vincularse con otros/as en la aventura de ensayar y vivir experiencias pedagógicas alternativas.

\section{Referencias}

Apple, M. (2012). Poder, conocimiento y reforma educacional. Miño y Dávila Editores.

Behares, L. (2011). Enseñanza y producción de conocimiento. La noción de enseñanza en las políticas universitarias uruguayas. Universidad de la República.

Burdín, G. (2019). Uruguay: otra agenda para los indignados. Razones y personas. http://www.razonesypersonas.com/2019/03/uruguay-otra-agenda-para-los-indignados.html

Cano, A. y Castro, D. (2016). La extensión universitaria en la transformación de la educación superior. El caso de Uruguay. Andamios, 13(31), 313-337.

Cano, A.; Martinis, P. y Paleso, A. (2015). Diálogo de saberes entre Universidad y Enseñanza Media: búsquedas y fundamentos de un Espacio de Formación Integral. En García, Pérez y Rak, Memoria que es vida abierta. Diálogo de saberes a 40 años de la Huelga General. Universidad de la República.

Cano, A., Cavalli, V., Cassanello, C. y Caggiani, J. (2019). Educación y territorio: abordajes desde el Programa Integral Metropolitano de la Universidad de la República. +E: Revista de Extensión Universitaria, 9, 53-68.

Chevallard, Y. (1998). La transposición didáctica, del saber sabio al saber enseñado. Aique.

Dufour, D.-R. (2009). El arte de reducir cabezas. Sobre la nueva servidumbre del hombre liberado en la era del capitalismo total. Paidós.

Falero, A. (2012). Los enclaves informacionales de la periferia capitalista: el caso de Zonamérica en Uruguay. Un enfoque desde la sociología. Universidad de la República. 
Fernández Christlieb, P. (2019). Todos los psicólogos sociales: recapitulación de cuatro o cinco décadas. Athenea Digital, 19(1).

Fernández, A. (1998). La sexualidad atrapada de la Srta maestra. Nueva Visión.

García Canclini, N. (2018). "Hacer que la aglomeración parezca ciudad" [Prólogo al libro de Juan Villoro El vértigo horizontal. Una ciudad Ilamada México]. Almadía.

García V., Pérez M. y Rak, G. (2015). Memoria que es vida abierta. Diálogo de saberes a 40 años de la Huelga General. Universidad de la República.

Gómez, M. y Corenstein, M. (2014), Reconfiguración de lo educativo en América Latina. Experiencias pedagógicas alternativas. UNAM.

Gómez, M., Hamui, L y Corenstein, M. (2014) Huellas, recortes y nociones ordenadoras, en Reconfiguración de lo educativo en América Latina. Experiencias pedagógicas alternativas. UNAM (pp. 33-65).

Larrosa, J. (2003). La experiencia y sus lenguajes. Serie Encuentros y Seminarios. Ministerio de Educación de la República Argentina.

Herner, T. (2009). Territorio, desterritorialización y reterritorialización: un abordaje teórico desde la perspectiva de Deleuze y Guattari. Huellas, 13, 158-171.

Martinis, P. (2016). Sujeto de la educación y discurso pedagógico (social) $\mathrm{O}$ acerca de la no continuidad entre sujetos sociales y sujetos educativos. En J. Camors, Reflexiones sobre las prácticas educativas en Brasil y Uruguay: pedagogía social y educación social. Montevideo: FHCE (pp. 39-52).

Mendy, M. (2012). El territorio PIM como espacio productivo. En Laboratorio Barrial de Experiencias. Extensión Libros (pp. 80-97).

Ministerio de Vivienda Ordenamiento Territorial y Medio Ambiente, mVotma (2019). "Asentamientos recientes en Uruguay: un estudio exploratorio. Informe Técnico", Unidad de Evaluación y Monitoreo del Programa de Mejoramiento de Barrios del Ministerio de Vivienda Ordenamiento Territorial y Medio Ambiente, Montevideo.

Oficina de Planeamiento y Presupuesto-Opp. (2019). Observatorio Territorial del Uruguay de la Oficina de Planeamiento y Presupuesto. http://www.otu.opp.gub.uy/perfiles/montevideo/municipio-f [fecha de consulta: 10/12/2019]

Pérez, M.; Ceroni, M.; Falero, A.; Soto, G. y Rodríguez, A. (2018). Discusiones necesarias: prácticas integrales y problemas teórico-metodológicos a partir del proyecto de investigación "Territorio controlado". En Universidad y territorio. A 10 años del Programa Integral Metropolitano y 100 de la Reforma de Córdoba. PIM. 
Rancière, J. (2007). El maestro ignorante. Cinco lecciones sobre la emancipación intelectual. Libros del Zorzal.

Rico, Á. (2005). Cómo nos domina la clase gobernante. Orden político y obediencia social en la democracia posdictadura. Uruguay 19852005. Trilce.

Santiviago, C.; Bouzó, A. y De León, F. (2015). Tutorías entre iguales de interfase: una práctica innovadora. Revista Latinoamericana de Educación Inclusiva, 9, 59-71.

Sztulwark, D. (2019). La ofensiva sensible. Neoliberalismo, populismo y el reverso de lo político. Caja Negra.

Tommasino, H. y Stevenazzi, F. (2016). Reflexiones en torno a las prácticas integrales en la Universidad de la República. Revista de Extensión Universitaria $+E, 6,120-129$.

Zavala, A. (2012). Mi clase de historia bajo la lupa. Trilce. 